\title{
Caloric restriction in female reproduction: is it beneficial or detrimental?
}

\author{
Jiayi Sun ${ }^{1,2}$, Xin Shen ${ }^{1}$, Hui Liu', Siying Lu' ${ }^{1}$ Jing Peng ${ }^{3^{*}}$ and Haibin Kuang ${ }^{1,4^{*}}$ (D)
}

\begin{abstract}
Caloric restriction (CR), an energy-restricted intervention with undernutrition instead of malnutrition, is widely known to prolong lifespan and protect against the age-related deteriorations. Recently it is found that CR significantly affects female reproduction via hypothalamic (corticotropin releasing hormone, neuropeptide Y, agoutirelated peptide) and peripheral (leptin, ghrelin, insulin, insulin-like growth factor) mediators, which can regulate the energy homeostasis. Although CR reduces the fertility in female mammals, it exerts positive effects like preserving reproductive capacity. In this review, we aim to discuss the comprehensive effects of CR on the central hypothalamus-pituitary-gonad axis and peripheral ovary and uterus. In addition, we emphasize the influence of CR during pregnancy and highlight the relationship between $C R$ and reproductive-associated diseases. Fully understanding and analyzing the effects of $C R$ on the female reproduction could provide better strategies for the management and prevention of female reproductive dysfunctions.
\end{abstract}

Keywords: Caloric restriction, Undernutrition, Reproduction, Energy, Female

\section{Introduction}

Caloric restriction (CR) is a dietary intervention that restricts the energy intake and induces undernutrition without malnutrition [1]. CR is also termed energy restriction/deficiency, food restriction, dietary restriction and negative energy balance $[1,2]$. In the 1930s, McCay et al. [3] first discovered that CR increased the lifespan of rats who were restricted in food intake at the weaning or 2 weeks after the weaning. To date, CR is generally considered to prolong the mean as well as maximum lifespan and delay age-related deleterious alternations in diverse species, from yeast to mammals $[1,4]$.

Recently a hypothesized explanation of CR longevityextending effect, which is based on the disposable soma theory of aging, is that energy resource is reallocated

\footnotetext{
*Correspondence: 879332555@qq.com; kuanghaibin@ncu.edu.cn ${ }^{3}$ Department of Gynecology, Nanchang HongDu Hospital of Traditional Chinese Medicine, 264 MinDe Road, Nanchang, Jiangxi 330006, People's Republic of China

'Department of Physiology, Basic Medical College, Nanchang University, Nanchang, Jiangxi 330006, People's Republic of China

Full list of author information is available at the end of the article
}

from reproduction to somatic maintenance [5, 6]. Indeed, $\mathrm{CR}$ inhibits reproductive functions for long life in both sexes of invertebrates and vertebrates, and this effect is significantly stronger in laboratory model species. It is demonstrated that the reproductive traits with more energy expenditure suffer higher reductions. In most experiments, females are exposed more reproductive costs than males under CR, so females suffer a larger and more significant elongation in lifespan than males [6].

It is well-known that CR impairs female reproduction, but CR can also benefit it. Selesniemi et al. [7] reported that adult-onset $\mathrm{CR}$ enables to maintain activities of reproductive axis in aged female mice. Nowadays, more and more obese even normal-weight women go on a diet to achieve a beautiful figure. Therefore, it is necessary to have a systematic understanding that whether CR induced by dieting is favorable or harmful on female reproduction. In this review, we discuss the effects of $\mathrm{CR}$ in hypothalamus-pituitary-ovarian (HPO) axis, ovary and uterus. In addition, we investigate the influence of $\mathrm{CR}$

(c) The Author(s). 2021 Open Access This article is licensed under a Creative Commons Attribution 4.0 International License, which permits use, sharing, adaptation, distribution and reproduction in any medium or format, as long as you give appropriate credit to the original author(s) and the source, provide a link to the Creative Commons licence, and indicate if changes were made. The images or other third party material in this article are included in the article's Creative Commons licence, unless indicated otherwise in a credit line to the material. If material is not included in the article's Creative Commons licence and your intended use is not permitted by statutory regulation or exceeds the permitted use, you will need to obtain permission directly from the copyright holder. To view a copy of this licence, visit http://creativecommons.org/licenses/by/4.0/ The Creative Commons Public Domain Dedication waiver (http://creativecommons.org/publicdomain/zero/1.0/) applies to the data made available in this article, unless otherwise stated in a credit line to the data. 
during pregnancy and highlight the potential role of CR in female reproductive-associated diseases.

\section{The roles of CR in HPO axis}

Coordination of HPO axis with mediators controlling energy homeostasis

In all examined mammals, two main hypothalamic populations of kisspeptin (kiss1) neurons localize in caudal arcuate nucleus (ARC) and rostral preoptic area (POA). ARC kisspeptin neuron (Kiss $1^{\mathrm{ARC}}$ ) is also referred as KNDy neuron because it co-expresses the positive autoregulator neurokinin $B(\mathrm{NKB})$ and the negative autoregulator dynorphin (DYN). Kisspeptin neurons in both ARC and POA positively innervate GnRH neurons via kiss1 receptor (kiss1r). As following studies are predominantly based on laboratory rodents, we just discuss the differences of kisspeptin neurons between rodents and humans. One difference is that the rostral population in rodents is collectively located in the rostral periventricular area of the third ventricle (RP3V), which consists of the anteroventral periventricular nucleus (AVPV) and the periventricular nucleus (PeN). The POA kisspeptin neurons in humans reside more dispersedly. The other one is that in rodents, Kiss $1^{\text {ARC }}$ is implicated in negative feedback of estrogen while AVPV kisspeptin neuron $\left(\mathrm{Kiss}^{\mathrm{AVPV}}\right)$ is implicated in positive feedback. In contrast, both negative and positive feedback are mediated by Kis$s 1^{\text {ARC }}$ in humans $[8,9]$. Both hypothalamic (CRH neurons, ARC NPY/AgRP neurons, ARC POMC/CART neurons) and peripheral (leptin, insulin, ghrelin, IGF-1) mediators are response to energy balance, and their relationships with HPO axis are shown in Figs. 1 and 2 respectively. Noticeably, kisspeptin neurons are the critical hubs of these linkages.

\section{Hypothalamic mediators}

Figure 1a indicates that some metabotropic neurons in hypothalamus enable to regulate HPO axis. Corticotropin releasing hormone $(\mathrm{CRH})$ neurons in hypothalamus of adult female rats directly inhibit Kiss $1^{\text {ARC }}$ and Kiss $1^{\text {AVPV }}$ through CRH receptors [10]. The orexigenic neuropeptide $\mathrm{Y}(\mathrm{NPY})$ /agouti-related peptide (AgRP) neurons in ARC are negative to HPO axis. Padilla et al. [11] discovered that AgRP neurons in mice give inhibitory innervation to Kiss ${ }^{\text {ARC }}$ and Kiss $1^{\text {AVPV }}$, but they do not give any neurotransmitter or neuropeptide to GnRH neurons. Although GnRH neurons in female rodents express both stimulatory NPY Y4 receptors and inhibitory Y1 receptors, the latter is responsible for the major effect of NPY peptide on GnRH neurons [12, 13]. GnRH neurons in adult rats also express inhibitory NPY Y5 receptors [14]. The anorexigenic pro-opiomelanocortin (POMC)/cocaine- and amphetamineregulated transcript (CART) neurons in ARC are positive to HPO axis. In female mice, the excitatory effect of POMC neurons to $\mathrm{GnRH}$ neurons is predominantly mediated by the POMC-cleaved product $\alpha$-melanocyte stimulating hormone $(\alpha-\mathrm{MSH})$, which excites GnRH neurons via both melanocortin receptor 3 (MC3R) and MC4R [12]. However,

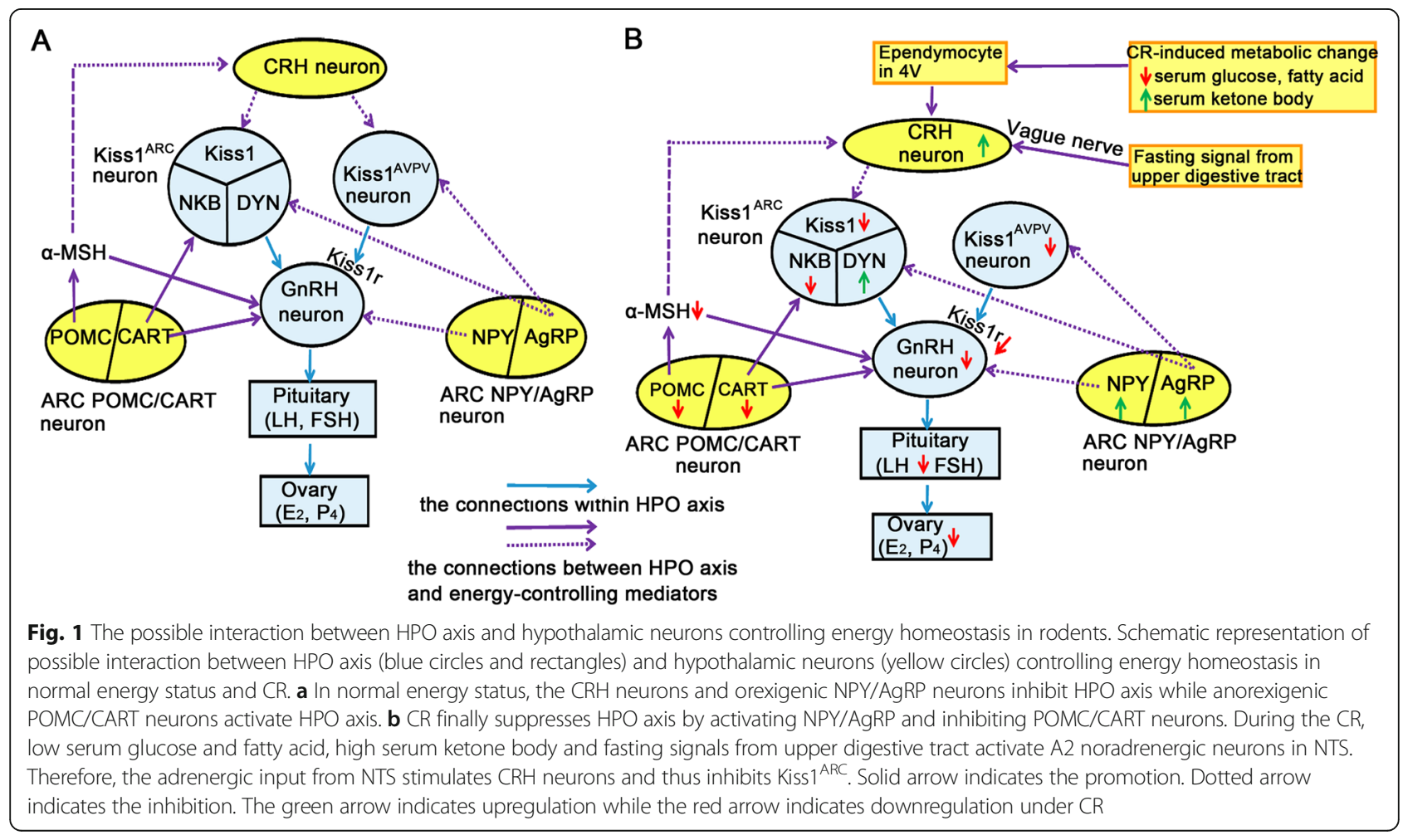




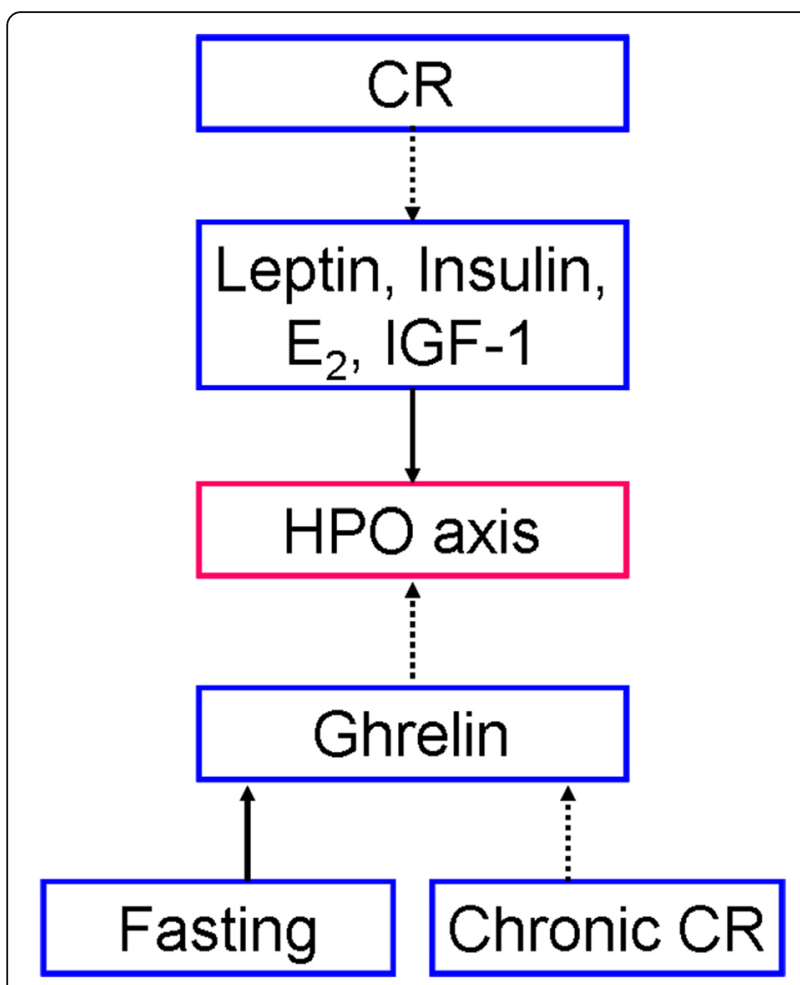

Fig. 2 The interaction between peripheral hormones and HPO axis. The anorexigenic factors such as leptin, insulin, estradiol $\left(E_{2}\right)$ and insulin-like growth factor (IGF-1) activate HPO axis while the orexigenic ghrelin inhibits HPO axis. CR downregulates the expressions of leptin, insulin, $E_{2}$ and IGF-1, which will lead to the inhibition of HPO axis. Ghrelin expression is upregulated during fasting but it is downregulated during chronic CR. Solid arrow indicates the promotion. Dotted arrow indicates the inhibition

$\alpha$-MSH inhibits CRH neurons via MC4R [15]. The experiment in female mice found that AgRP peptide, which is an antagonist of melanocortin receptors, attenuates the MC4Rmediated activation on GnRH neurons [16]. Interestingly, POMC neurons in female mice negatively innervate NPY/ AgRP neurons and this innervation is enhanced by estradiol $\left(E_{2}\right)$ [17]. It has been discovered that CART postsynaptically depolarize Kiss $1^{\mathrm{ARC}}$ and GnRH neurons in female rats [18]. Collectively, in normal energy status, CRH neurons and ARC NPY/AgRP neurons inhibit HPO axis while ARC POMC/CART neurons activate HPO axis.

\section{Leptin}

Leptin is an adipocyte-derived anorexigenic factor. The stimulatory effect of leptin on HPO axis is dominant at hypothalamic level. Leptin directly activates Kiss $1^{\text {ARC }}$ in mice, sheep and guinea pigs. It is summarized that leptin deficiency in mice decreases not only ARC kiss1 mRNA level but also the amounts of Kiss $1^{\text {AVPV }}$ [19]. Although GnRH neurons do not express leptin receptors (LepRs) [19-21], leptin in rodents can indirectly stimulate them through the neurons in hypothalamic premammillary nucleus (PMV) [22]. Generally, ARC POMC/CART neurons express facilitatory LepR while ARC NPY/AgRP neurons express inhibitory LepR [15]. Indeed, leptin can exert female-specific stimulatory effect on $\mathrm{GnRH}$ neurons via CART in adult rats [14]. However, strong evidences from laboratory rodents indicate that NPY-Y1/Y5 receptor signaling [2, 14] and MC3R/MC4R-mediated signaling [21] are leptin-independent.

\section{Ghrelin}

Ghrelin is the only circulating stomach-derived peptide and it functionally antagonizes leptin [23]. Ghrelin predominantly inhibits HPO axis [23-25] through following 3 approaches: (i) Ghrelin directly inhibits Kiss1 ${ }^{\mathrm{AVPV}}$ [24] and GnRH neurons [25] in female rats. (ii) Ghrelin promotes the release of $\mathrm{CRH}$ in female rhesus monkeys, so it can indirectly repress GnRH neurons $[23,26]$. (iii) Ghrelin stimulates NPY neurons and subsequently inhibits POMC neurons in rodents [27]. Although ghrelin primarily suppresses gonadotropin secretion in female animals and women [28], it benefits basal luteinizing hormone (LH) and follicle-stimulating hormone (FSH) secretion in female rats [25]. Ghrelin in mouse placenta negatively modulates early embryonic development [23].

\section{Insulin}

The anorexigenic insulin is found to activate HPO axis. Although in vitro mice study discovered that insulin can directly modulate GnRH neurons, in vivo studies of adult ewes and mice gave an opposite evidence [29,30]. Indeed, insulin activates Kiss1 ${ }^{\mathrm{ARC}}$ in mice via functional insulin receptors [31]. Also, in laboratory animals, insulin excites ARC POMC neurons and suppresses NPY/AgRP neurons [30]. In addition, insulin in mice directly stimulates gonadotropes to enhance the LH mRNA expression [32].

\section{IGF-1}

The hepatic insulin-like growth factor-1 (IGF-1) enables to activate HPO axis. Firstly, both intracerebroventricularinfused and peripherally injected IGF-1 in the prepubertal female rodents can directly activates Kiss $1^{\mathrm{AVPV}}$ and $\mathrm{GnRH}$ neurons, thus leading to a precocious puberty [29]. Secondly, experiment in female rats demonstrated that low circulating IGF-1 caused by CR inhibits the pituitary gonadotropes, therefore represses the secretion of LH, FSH and thus estrogen [33]. Thirdly, IGF-1 signaling in ovine induces the activation of primordial follicles [34]. In addition, IGF-1 in mammalian ovary stimulates steroidogenesis, either alone or in synergy with gonadotropins [35].

\section{CR-induced alternations negatively affect HPO axis}

It is found that negative energy balance in female mammals inhibit HPO axis by suppressing pulsatile $\mathrm{GnRH}$ 
secretion and then attenuating pulsatile $\mathrm{LH}$ release from pituitary, resulting in infertility [2, 20,36]. Noticeably, the experiments in adult female rodents discovered that the extent of this inhibition is different between acute fasting and chronic CR. The former marginally inhibits HPO axis because it hardly changes KNDy-related gene expression, but it suppresses Kiss1r expression on GnRH neurons. The latter totally inhibit HPO axis because it not only decreases ARC kiss1, NKB, AVPV kiss1 and kiss1r expression but also increases DYN expression [20, $36]$. Under CR, the diverse changes in both central and peripheral regulators contribute to HPO axis inhibition.

Figure $1 \mathrm{~b}$ demonstrates that alternations in hypothalamic mediators inhibit HPO axis under CR. Initially, a series of rodent experiments discovered that $\mathrm{CR}$ activates AgRP neurons [11] and increases NPY mRNA level [37]. Also, CR decreases the expression of POMC [2] and CART [18]. Therefore, the activation of ARC NPY/ AgRP neurons and the suppression of ARC POMC/ CART neurons enable to inhibit HPO axis. Secondly, studies in laboratory animals (mainly rodents) found that there are two avenues that finally activate CRH neurons. One is that ependymocytes in the fourth ventricle $(4 \mathrm{~V})$ sense CR-induced high ketone-body availability and low glucose as well as fatty acid availabilities. Then these ependymocytes send the energy-deficient information to A2 noradrenergic neurons in solitary tract nucleus (NTS) $[38,39]$. The other pathway is that fasting signals from upper digestive tract stimulate NTS A2 noradrenergic neurons via vague nerve [39]. Converging these two pathways, CRH neurons that are received the stimulatory input from A2 noradrenergic neurons [38, 39] release high level of CRH and thus inhibits Kiss1 ${ }^{\text {ARC }}$ [40]. Interestingly, Deura et al. [40] discovered that in female rats, the $\mathrm{CR}$ sensor ependymocytes may also stimulate A6 noradrenergic neurons in NTS and then activate $\mathrm{CRH}$ neurons. These CRH neurons inhibit Kiss $1^{\mathrm{AVPV}}$.

Fig. 2 demonstrates that alternations of peripheral hormones inhibits HPO axis under CR. In mammals (mainly rodents), CR decreases serum leptin [15], insulin [2, 41] and insulin-like growth factor-1 (IGF-1) [2, 33, 41]. This series of hormonal changes enable to repress pulsatile $\mathrm{LH}$ secretion, therefore contributing to the inhibitory effect of CR on HPO axis $[2,15,20,33]$. However, a strong evidence from adult female rats shows that hypoleptinaemia is not the crucial signal leading to the inhibition of ARC kiss1 and LH during CR [20]. Although serum ghrelin is decreased during fasting, it is increased in chronic CR [2]. In ovariectomized estrogen-replaced rats, fasting-induced hyperghrelinaemia suppresses pulsatile LH secretion [24]. In addition, $C R$ decreases plasma $E_{2}$ in rodents and ruminants [2, 42-45], which is consistent with HPO axis inhibition. Interestingly, $\mathrm{CR}$ enhances the negative feedback (mice) $[2,36]$ and attenuates the positive feedback (rhesus monkeys) [46] of $E_{2}$ on $\mathrm{HPO}$ axis. It is also found that $\mathrm{E}_{2}$ as an anorexigenic factor enables to inhibit ARC NPY/ AgRP neurons and activate ARC POMC neurons [31]. Therefore, low $E_{2}$ level caused by $\mathrm{CR}$ also contributes to the inhibition of HPO axis. Intriguingly, chronic CR in adult female rodents reduces serum LH in the presence of estrogen $[36,42]$ but increases serum LH in the absence of estrogen $[36,47]$, suggesting that the existence of estrogen is necessary in the effect of CR on HPO axis.

\section{CR delays the onset of female puberty}

Puberty is started by re-awaking the GnRH pulse generator that is dormant before $[29,48]$. Recent experiments have discovered that pubertal timing in female mammals is delayed by CR [30, 48], and it is restored once ad libitum (AL)-feeding was resumed [21]. It is generally accepted that hypothalamic kiss1 is a gatekeeper of puberty $[19,49]$. Therefore, reduced hypothalamic kiss 1 expression during prepubertal period may be the key mechanism of CR deferring puberty onset.

The changes in brain under $\mathrm{CR}$ delay the timing of puberty. The experiment in immature female rodents found that hypothalamic AMP-activated protein kinase (AMPK)-kisspeptin signaling regulates puberty onset. Hypothalamic AMPK, which can sense whole-body energy status, is found to be activated (i.e. phosphorylated) by $C R$ and thus postpone the onset of puberty. More specifically, CR increases pAMPK level in Kiss $1^{\text {ARC }}$ and thus suppresses ARC kiss1 gene expression. However, the effect of hypothalamic pAMPK on Kiss $1^{\mathrm{AVPV}}$ is not discovered [50]. In addition, the experiment in female rats discovered that $C R$ defers pubertal maturation by attenuating NKB-neurokinin-3 receptor (NK3R) signaling [51] as NKB is a positive autoregulator of Kiss ${ }^{\text {ARC }}$.

Studies in rodents and humans demonstrated that leptin is just a permissive factor of pubertal onset because it alone cannot advance the onset of puberty [19]. It has been discovered that the suppression of leptin/ LepR-kisspeptin/Kiss1r-GnRH signaling in female rats mediates the inhibitory effect of $\mathrm{CR}$ on puberty onset [48]. The novel leptin- $\alpha-M S H-k i s s p e p t i n-G n R H$ pathway in rats and mice is a possible mechanism of pubertal delay caused by CR [52]. High serum ghrelin can also delay puberty onset, but female rats are less sensitive to the effect of ghrelin than males [23]. It is discovered that the production of hypothalamic PAMPK is repressed by anorexigenic signals (e.g. leptin, insulin and $E_{2}$ ) while is induced by orexigenic signals (e.g. ghrelin) [53], so it may be a considerable method for $\mathrm{CR}$ to defer pubertal timing.

\section{The roles of CR in ovary}

\section{The roles of $C R$ in folliculogenesis}

Originally, studies of female rodents with $\mathrm{CR}$ initiated at weaning have proved that $\mathrm{CR}$ extended reproductive 
lifespan. However, CR during ablactation also impeded adolescent growth and sexual maturation, which interfered experiments [54]. Fortunately, recent studies of female rodents with adult-onset CR effectively excluded these interference factors. These experiments discovered that $\mathrm{CR}$ delays ovary aging through the maintenance of ovarian oocyte-containing follicle reserve [7, 42, 55-59] and good egg quality $[7,60,61]$. Although CR reduces fertility, it retains reproductive capacity and prolongs the reproductive lifespan. Therefore, when $\mathrm{CR}$ rodents are returned to AL feeding, their reproductive performances (i.e. fertility, fecundity and postnatal offspring survival rate) rebound or are even higher than that in AL condition [7].

\section{$C R$ benefits follicle pool reservation}

The maintenance of follicle pool can reduce fertility and prevent premature ovarian failure [7, 57]. Compared with AL control group, $\mathrm{CR}$ in adult female rodents significantly increased the number of primordial follicles (PMFs). This finding indicates that CR reduces the rate of PMF activation, thus inhibiting the transition from primordial follicle to primary follicle [7, 42, 55-59]. Secondly, the number of secondary follicles, antral follicles and corpus luteum were dramatically lower in CR-fed rodents. This observation suggests that $C R$ suppresses the ovarian follicle development at different stages, follicle maturation and ovulation $[39,51,53,54]$. CR inhibits follicle atresia because CR-fed mice and rats had the significantly low amount of atretic follicles $[7,42,56$, 57]. Also, CR inhibits the total follicle loss as the dramatically increased number of total surviving follicles was seen in CR-fed rodents [57-59]. Although low fertility is observed in CR-fed mice, the capacity of fertility is augmented. Therefore, the fertility rebounds once AL-feeding is resumed [7]. It is noticed that CR also can augment the follicle pool and elongate the ovarian lifespan in adult female rats treated with chemotherapy [4]. SIRT1720, which partially mimics CR, achieves the similar effect in high-fat diet-induced obesity [58].

Figure $3 \mathrm{a}$ shows the mechanism that $\mathrm{CR}$ increases ovarian follicle pool. Initially it is found that CR enhances SIRT1, FOXO3a, NRF1 and SIRT6 gene expression in rodent ovary. More specifically, SIRT1, FOXO3a and SIRT6 are predominantly expressed in the oocytes and hardly expressed in the granulosa cells. Due to SIRT1-FOXO3a-NRF1 complex formed on the SIRT6 promoter can upregulate SIRT6 expression, activation of SIRT1/FOXO3a/NRF1-SIRT6 signaling is one of the avenues which $C R$ hinders the transition from PMFs to primary follicles [57-59, 62, 63]. SIRT1 upregulation by $\mathrm{CR}$ is important because it can also downregulate both p53 [53, 54] and mTOR complex 1 (mTORC1) [42, 58, 63] gene expression in rodent ovary. The evidence that low p53 inhibits follicle atresia is support by following studies: (i) p53 protein in rats is expressed in the apoptotic granulosa cells of atretic follicles [64]. (ii) Reduced p53 level in rat ovary is related to a significant decrease in the amount of apoptotic granulosa cells as well as atretic follicles [65]. (iii) p53 in mice is implicated in the regulation and selection of oocytes at checkpoints, such that oocytes that would otherwise be lost may persist when p53 is absent or reduced [66]. Recent studies from rodent models discovered that SIRT1 suppresses mTORC1-p70S6 kinase (S6K1)-ribosomal protein S6 (rpS6) signaling, thus preserving PMFs in quiescent state $[42,58,63]$. The most critical intra-oocyte signaling that controls PMF activation is the PI3K-Akt signaling. CR in female mice inhibits PI3K-Akt signaling and subsequently represses FOXO3a phosphorylation. The nonphosphorylated FOXO3a proteins are remained in oocyte nucleus, culminating in sustaining quiescent PMFs and thus maintaining ovarian follicle pool [55, 67]. Interestingly, it is found that CR preserving PMF pool is associated with low IGF-1 in rat ovary [33], and IGF-1 indeed activates PMFs via PI3K-Akt pathway in sheep ovary [34]. Therefore, CR may preserve PMF pool of rats by inhibiting IGF-1-PI3K-Akt signaling. It is also summarized that this signaling can upregulate mTORC1 expression [68]. In addition, CR overexpressing IGF-1 receptors (IGF-1Rs) may mediate the inhibition of follicle atresia because IGF1 Rs enable to antagonize cell apoptosis [33].

\section{$C R$ benefits egg quality}

Two experiments in adult female mice give compelling evidence that $C R$ enables to overcome the aging-related deterioration of egg quality: (i) The fecundity and postnatal offspring survival rate were remarkably increased in CRthen-AL fed mice [7]. (ii) The aging-related increases in aneuploidy, chromosomal misalignment on the metaphase plate, meiotic spindle abnormalities, mitochondrial aggregation and decreased ATP level, which were occurred in oocyte of AL-fed mice, were not exhibited in age-matched CR mice [61]. Therefore, good egg quality maintained by $\mathrm{CR}$ has a beneficial effect on oocyte meiotic maturation and fertilization, pre-implantation embryonic development, pregnancy success rate and embryo quality [60, 61].

The mechanism of CR keeping good egg quality is also shown in Fig. 3b. CR in adult mice upregulates mitochondrial SIRT3 in oocyte, and SIRT3 protect oocytes from the synthesis of mitochondrial reactive oxygen species (ROS). Therefore, high SIRT3 attenuates oxidative stress which declines oocyte quality with age $[61,62]$. Also, CR in adult mice dramatically improves meiotic spindle assembly and maintenance, so it prevents oocyte aneuploid and chromosomal misalignment. In addition, $\mathrm{CR}$ enables to prevent the occurrence of aging-related mitochondrial dysfunction because it can appropriately arrange mitochondria in oocytes [61]. Although CR 


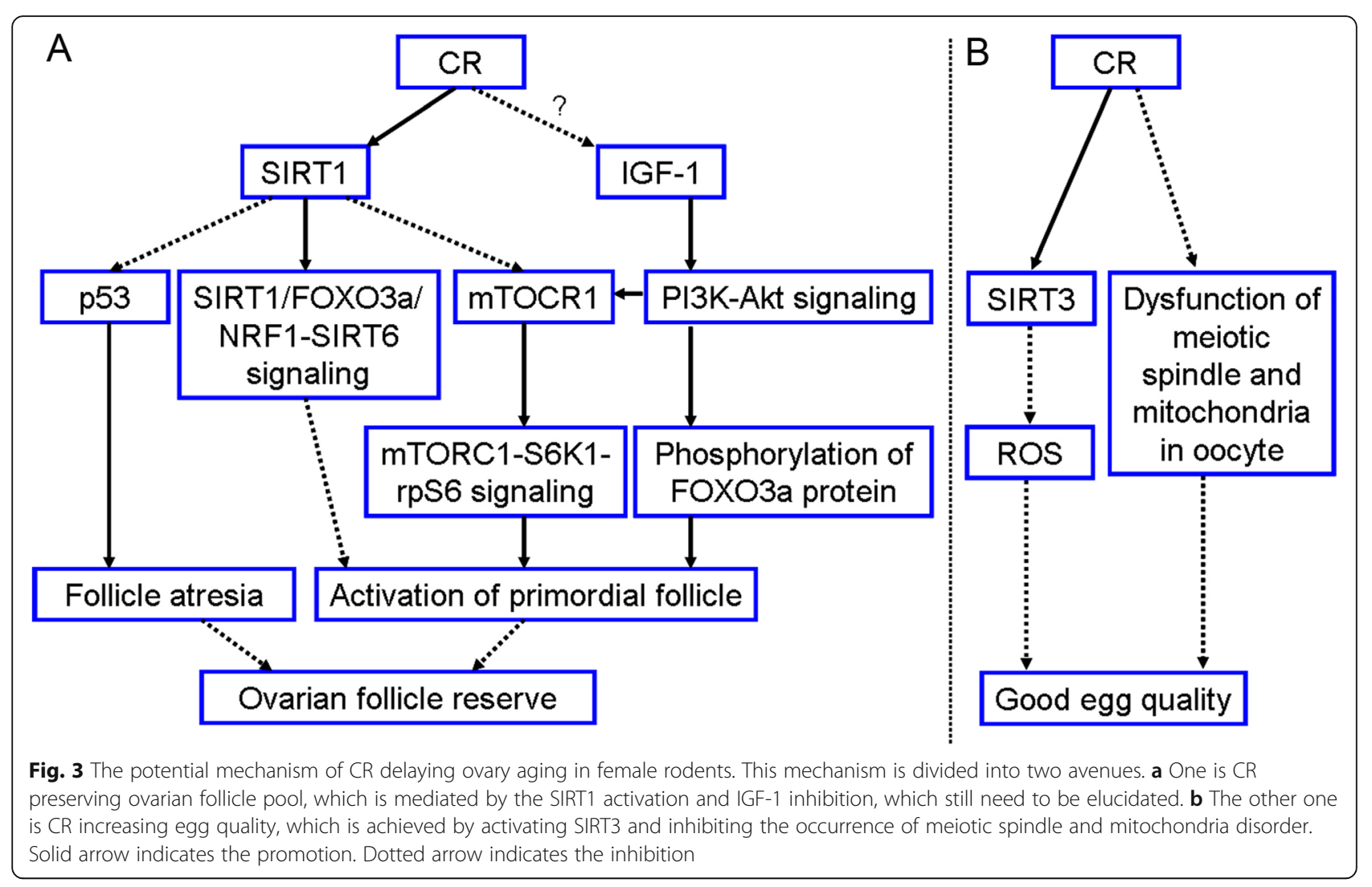

upregulates PGC-1 $\alpha$ expression [60], Selesniemi et al. [61] discovered that loss of PGC-1 $\alpha$ can reproduce the positive effect of $\mathrm{CR}$ on egg quality in aging female mice.

It is generally known that rodent models do not have true menses like humans. In humans, high size of PMF pool and slow rate of oocyte depletion are essential determinants of delayed menopause onset $[69,70]$. As $\mathrm{CR}$ increases the number of PMFs and suppresses follicle development of rodents, it may have similar effect on human follicles. Therefore, CR seems to delay menopause onset and prolong reproductive lifespan of humans. However, the study of women who were exposed to Dutch famine discovered that CR decreases age at natural menopause, especially when occurring in early life [71]. The reason of this phenomenon is unknown. Another experiment showed an enigmatic discovery that the improvement of fecundity was observed in rabbits with CR alone [72]. Therefore, further studies are needed to explain these confusing findings.

\section{The roles of $C R$ in ovulation}

CR delays ovulation in mice [57], rhesus monkey [46], buffalo heifer [45] and women [73]. However, ovulation is increased in CR-then-AL-fed mice [7, 43]. There are two possible mechanisms of $\mathrm{CR}$ inhibiting ovulation.
One is that in women $\mathrm{CR}$ reduces FSH secretion below the basal level. FSH deficiency cannot stimulate the growth of secondary follicles and thus the generation of dominant follicles where $E_{2}$ is synthesized. Therefore, $E_{2}$ concentration is too low to trigger an LH surge $[74,75]$. In addition, low intra-ovarian IGF-1 caused by CR impedes $E_{2}$ synthesis, thus inhibiting $\mathrm{LH}$ surge generation $[35,75,76]$. The other one found by Lujan et al. [46] is that $\mathrm{CR}$ inhibits gonadotropin surges in ovariectomized rhesus monkeys supplied with exogenous $\mathrm{E}_{2}$ and progesterone $\left(\mathrm{P}_{4}\right)$, and the researchers summarized that $\mathrm{CR}$ inhibits gonadotropin surges in most CR-treated animals because CR impairs the hypothalamic response to the positive feedback of $E_{2}$.

\section{The roles of $C R$ in steroidogenesis}

It has been discovered that $C R$ reduces plasma $E_{2}$. The discovery that chronic $\mathrm{CR}$ increase the expression of estrogen receptors but do not change the expression of androgen receptors in mice ovary also indicates the decreased level of serum $E_{2}$ under CR [43]. Here we hypothesize that CR inhibits $\mathrm{E}_{2}$ synthesis. One possible mechanism is provided by the experiment in beef heifers [44]. Heifers with CR had lower plasma insulin, IGF-1 and LH, therefore STAR gene expression in theca cells is decreased. STAR transports cholesterol from the outer to the inner mitochondrial 
membrane, and then the intra-mitochondrial cholesterol can be converted into pregnenolone, resulting in $E_{2}$ synthesis. As a result, CR-treated beef heifers reduced $E_{2}$ production in dominant follicle. Another possible mechanism is related to intra-ovarian IGF-1/IGF-1R signaling. IGF-1 alone can increase the synthesis of $\mathrm{E}_{2}$, and it can synergistically activate $\mathrm{FSH}$-induced aromatase that catalyzes the synthesis of $E_{2}$ in rodents and humans $[35,75]$, so CR suppresses $E_{2}$ synthesis. In addition, $C R$ females have lower number of antral follicle where $E_{2}$ is mainly synthesized.

It is less well-known about the effect of $\mathrm{CR}$ on $\mathrm{P}_{4}$ synthesis. CR reduces serum $\mathrm{P}_{4}$ in mice [56], buffalo heifer [45] and women [73]. However, it is found that there was no difference of follicular fluid $\mathrm{P}_{4}$ between beef heifers fed a diet of 1.2 times maintenance $(\mathrm{M})$ and that fed a $0.4 \mathrm{M}$ diet [44]. It is hypothesized that CR inhibits $\mathrm{P}_{4}$ production because $\mathrm{CR}$ females have less corpus luteum where most $\mathrm{P}_{4}$ is synthesized. In addition, low IGF-1 level may decrease $\mathrm{P}_{4}$ synthesis because IGF-1 alone or synergistically promotes $\mathrm{P}_{4}$ production [35].

\section{The roles of $C R$ in the uterus}

There are few experiments concentrating on the effect of $\mathrm{CR}$ on uterus. Basically, we can make sure that the reductions of serum $\mathrm{E}_{2}$ and $\mathrm{P}_{4}$ caused by $\mathrm{CR}$ impair endometrium development and function. The reason is that before ovulation $E_{2}$ stimulates the rapid proliferation of endometrial stromal and epithelial cells. Also, $E_{2}$ promotes the growth and vascularization of uterine glands. After ovulation, $\mathrm{P}_{4}$ produces a highly secretory endometrium and decidualizes the stromal cells to prepare an appropriate environment for implantation [74]. It is found that when women are exposed to CR during puberty, the mature GnRH neurons will become immature, increasing the risk of menstrual impairment [77].
The study in women proved that CR during reproductive age is related to irregular menses, and this deterioration becomes more serious if CR happens earlier. It is also discovered that $\mathrm{CR}$ during childhood prolongs the time from menarche to regular menses. However, CR during childhood seems not to negatively affect menstrual cycles in adulthood [78] (Table 1).

\section{The roles of $C R$ in pregnancy}

Placenta is a critical hub in the effect of CR on offspring's health

$\mathrm{CR}$ during pregnancy leads to maternal undernutrition (MUN). In mammals, MUN results in intrauterine growth restriction (IUGR) through reducing fetal nutrient availability, altering hormonal environment exposed to fetus and causing epigenetic changes in fetal genomes. These changes not only damage fetal health, but also increase the chronic disease susceptibility in postnatal life. Noticeably, placental alternation is a pivotal linkage of MUN to IUGR $[87,88]$.

Placenta is plastic to against exogenous insults. In women exposed to Dutch Famine during pregnancy, compensatory growth of placenta induced by MUN maintains consistent fetal nutrition to parturition, so the birthweight is normal [79] (Table 1). However, IUGR results if this adaptation alone cannot provide enough nutrients to ensure the normal fetal growth. In fact, impaired maternal-fetal circulation and nutrient transport system in placenta also mediate the influence of MUN on fetal development [87].

A series studies of humans who were exposed to Dutch Famine before birth discovered that MUN gives postnatal progeny the physical and cognitive impairments in life-long pattern. For example, MUN increases the prevalence of schizophrenia, coronary heart disease

Table 1 The main roles of CR in uterus, pregnancy and reproductive-related diseases

\begin{tabular}{|c|c|c|c|c|}
\hline Authors & Year & Species & Aspects & Influence of CR \\
\hline Elias et al. [78] & 2007 & Humans & Uterus & $\begin{array}{l}\text { CR during puberty relates to irregular menses, and CR during } \\
\text { childhood prolongs the time from menarche to regular menses. }\end{array}$ \\
\hline Lumey et al. [79] & 1998 & Humans & Pregnancy & CR in early pregnancy triggers compensatory growth of placenta. \\
\hline Roseboom et al. [80] & 2006 & Humans & Pregnancy & $\begin{array}{l}\text { Prenatal CR gives lasting negative consequences to offspring's } \\
\text { health, especially in early gestation. }\end{array}$ \\
\hline Harper et al. [81] & 2015 & Mice & Pregnancy & $\begin{array}{l}\text { CR during early gestation makes placental alternations reversible, } \\
\text { resulting in metabolically normal offspring. }\end{array}$ \\
\hline Harrath et al. [82] & 2017 & Rats & Pregnancy & $\begin{array}{l}\text { Female offspring exposed to prenatal CR have an early puberty } \\
\text { onset and a short reproductive lifespan. }\end{array}$ \\
\hline Yarde et al. [83] & 2013 & Humans & Pregnancy & $\begin{array}{l}\text { No relationship between prenatal } C R \text { and reproductive activities } \\
\text { of offspring. }\end{array}$ \\
\hline Fenichel et al. [84] & 2007 & Humans & Reproductive-related diseases & CR develops hypothalamic amenorrhea. \\
\hline Marzouk et al. [85] & 2015 & Humans & Reproductive-related diseases & $\begin{array}{l}\text { CR alleviates the deleterious conditions of PCOS patients with } \\
\text { obesity. }\end{array}$ \\
\hline Lope et al. [86] & 2019 & Humans & Reproductive-related diseases & CR reduces the incidence of breast cancer \\
\hline
\end{tabular}


and type 2 diabetes. This deleterious effect is most obvious in early gestation, elucidating that early pregnancy is the most pivotal and vulnerable period [80, 89] (Table 1). The reason is that MUN in early pregnancy can permanently alter placenta, so it proceeds to affect the fetus till parturition, culminating in impairing postnatal health $[81,88]$. In contrast, the observation in mice treated with $50 \% \mathrm{CR}$ from days1.5-11.5 of pregnancy discovered that mice with $\mathrm{CR}$ could have reversible placental changes during early pregnancy, and their adult offspring was metabolically normal. It has been proposed that fetal development of humans expends more time than mice, so the timescale in humans is long enough to convert reversible compensation into irreversible overcompensation. This fact may support the phenomenon that humans have an irreversible but mice have a reversible placental alternation [81] (Table 1). It was summarized by Harper et al. [81] that the duration of changes in the placenta determines the duration of programming on fetus. The species differences in the effect of early-gestational MUN on adult phenotype are attributed to the extent of placenta recovery.

\section{Effects of prenatal CR in offspring's reproduction}

Intriguingly, MUN affects reproductive performances of animal offspring. Two experiments in rats $[82,90]$ found that female offspring exposed to prenatal CR had an aberrant ovarian follicle population, resulting in premature ovarian failure and reduced reproductive lifespan. Initially, these offspring had a significantly lower amount of PMFs and higher amount of primary follicles in prepubertal period. This observation indicates that in female descendants, PMF pool is affected by MUN during fetal life, and MUN advances the folliculogenesis, resulting in an early puberty onset. When these offspring reach adulthood, the number of PMFs and growing follicles (i.e. secondary follicles, antral follicles) were significantly reduced, suggesting that MUN causes a short reproductive lifespan. The reason is that the expression of genes, which are crucial for follicle maturation and ovulation, was reduced by both increased ovarian oxidative stress and impaired capacity for repairing oxidative damage [90]. Collectively, the female rat offspring born to mother with MUN have a more intensive and timelimited reproductive lifespan, and they can reproduce more successfully $[82,90]$ (Table 1 ). The experiment in sheep had a similar finding [91].

Regard to humans, Painter et al. [92] discovered a similar finding that women born to mother with MUN could reproduce more successfully if they were fed with improved nutrition in their postnatal period. However, Lumey et al. [93] raised an objection to Painter's finding. He thought there was no difference in reproductive activities like delivery between women exposed to MUN during their fetal life and those not exposed to MUN during fetal life. And he attributed this inconsistent result to the fact that the Painter database was inappropriate and thus was not representative. In fact, Yarde et al. investigated mothers who were exposed to Dutch famine during gestation and discovered that MUN does not affect reproductive performances of offspring [83] (Table 1).

\section{The roles of CR in reproductive-related diseases}

In women, $\mathrm{CR}$ enables to develop hypothalamic amenorrhea. The direct pathology is the impairment of HPO axis. The reduced $\mathrm{GnRH}$ secretion attenuates the gonadotropin secretion, therefore ovarian follicle development and $E_{2}$ synthesis are inhibited. The insufficient $E_{2}$ concentration cannot trigger the pre-ovulatory gonadotropin surges, culminating in anovulation and amenorrhea. Also, the reduced plasma leptin and the increased plasma ghrelin, which represent the low energy status, compromise the function of HPO axis and thus result in amenorrhea. Cognitive-behavioral therapy is considered as the possible treatment of amenorrhea, and $\mathrm{E}_{2}$ level is the index to assess the extent of HPO axis recovery [74, 84] (Table 1).

Approximately 5-10\% reproductive-age women have polycystic ovary syndrome (PCOS), which is one of the commonest endocrine diseases. It is characterized by hyperandrogenism and chronic anovulation. Women with PCOS carry 2.7 -fold increased risk of endometrial carcinoma [85, 94]. Noticeably, CR exerts a benefit effect on obese PCOS patients. In obese young adult women with PCOS, CR-induced weight loss ameliorates androgen overproduction, restores ovulatory cyclicity, improves menstrual function and attenuates insulin resistance. Therefore, dietary weight loss is considered to become the first-line treatment in obese PCOS patients $[85,95]$ (Table 1). Interestingly, giving CR in advance increases the survival rate of prepubertal obese/ PCOS-prone rats when they encounter famine [96]. LH hypersecretion is observed in obese PCOS women, and CR usually attenuates pulsatile LH secretion in healthy women. However, daily LH secretion is still increased even these obese PCOS patients are treated with CR [97]. In addition, preserving $\mathrm{E}_{2}$-dependent negative feedback to LH can predict follicle maturation and ovulation in obese PCOS patients who are treated with CR [95].

In addition, another beneficial effect of $\mathrm{CR}$ displays on breast cancer. The study of women found that CR decreases the susceptibility of breast cancer. In contrast, excessive caloric intake increases the risk of developing BC. Researchers proposed that the combination of moderate $\mathrm{CR}$ and physical exercise is a prospective strategy to prevent breast cancer [86] (Table 1).

\section{Conclusion}

In this review, we summarize that $\mathrm{CR}$ exerts both positive and negative effects on female reproduction system. CR 
impairs HPO axis and indeed reduces fertility in female mammals. Kisspeptin neuron is the crucial hub that links low energy state and HPO axis. In this review, there are three differences between rodents and humans. Firstly, CR in rodents simultaneously increases reproductive capacity and prolongs fertility lifespan. In contrast, CR advances the menopause onset of women. Secondly, placental alternation is reversible in mice while irreversible in women when $C R$ takes place at pregnancy. Thirdly, prenatal CR shortens reproductive lifespan and increases fertility success in female rat offspring. However, it does not affect reproductive activities in human offspring. At last, we summarize that CR causes hypothalamic amenorrhea but ameliorates the deleterious condition of PCOS coupled with obesity. In addition, CR decreases the morbidity of breast cancer. The similarities and differences between animal and human results courage researchers to find the reasons behind them. Also, further studies focusing on human are needed.

\section{Abbreviations}

AgRP: Agouti-related peptide; AL: Ad libitum; AMPK: AMP-activated protein kinase; a-MSH: a-melanocyte stimulating hormone; ARC: Arcuate nucleus; AVPV: anteroventral periventricular nucleus; BC: Breast cancer; CART: Cocaineand amphetamine-regulated transcript; CR: Caloric restriction;

CRH: Corticotropin releasing hormone; DYN: Dynorphin; $\mathrm{E}_{2}$ : Estradiol; FSH: Follicle-stimulating hormone; GnRH: Gonadotropin-releasing hormone; HPO: Hypothalamus-pituitary-ovarian; IGF-1: Insulin-like growth factor; IGF1Rs: IGF-1 receptors; IUGR: Intrauterine growth restriction; kiss 1: Kisspeptin; Kiss 1 ${ }^{\text {ARC: }}$ ARC kisspeptin neuron; Kiss $1{ }^{\text {AVPV: }}$ : AVPV kisspeptin neuron; kiss1r: Kiss1-receptor; mTORC1: mTOR complex 1; MC3R: Melanocortin receptor 3; MUN: Maternal undernutrition; NKB: Neurokinin B; NK3R: Neurokinin-3 receptor; NPY: Neuropeptide Y; NTS: Solitary tract nucleus; PCOS: Polycystic ovary syndrome; PeN: Periventricular nucleus; PMV: Premammillary nucleus; POA: Preoptic area; POMC: Proopiomelanocortin; PMFs: Primordial follicles; P4: Progesterone; LepRs: Leptin receptors; LH: Luteinizing hormone; ROS: Reactive oxygen species; rpS6: Ribosomal protein S6; RP3V: Rostral periventricular area of the third ventricle; S6K1: p70S6 kinase; 4V: The fourth ventricle

\section{Acknowledgments}

None.

\section{Authors' contributions}

JYS, JP and HBK have been contributed to the initial literature search, acquisition, analysis and design the first draft of article. JYS, XS and HL have been included in review the manuscript and further edition. JYS and SL are responsible for designing illustrated Fig. JP and HBK proofread the final manuscript before submission. All authors read and approved the final manuscript.

\section{Funding}

This study was financially supported by the National Natural Science Foundation of China (32060203 and 81860283). The funders had no role in study design, data collection and analysis, interpretation of data, decision to publish, or preparation of the manuscript.

\section{Availability of data and materials}

All data supporting the conclusion of this article are included in this published article.

Ethics approval and consent to participate Not applicable.
Consent for publication

Not applicable.

\section{Competing interests}

The authors declare that they have no competing interests.

\section{Author details}

${ }^{1}$ Department of Physiology, Basic Medical College, Nanchang University, Nanchang, Jiangxi 330006, People's Republic of China. ${ }^{2}$ Department of Clinical medicine, School of Queen Mary, Nanchang University, Nanchang, China. ${ }^{3}$ Department of Gynecology, Nanchang HongDu Hospital of Traditional Chinese Medicine, 264 MinDe Road, Nanchang, Jiangxi 330006, People's Republic of China. ${ }^{4}$ Jiangxi Provincial Key Laboratory of Reproductive Physiology and Pathology, Medical Experimental Teaching Center of Nanchang University, Nanchang, China.

Received: 30 September 2020 Accepted: 6 December 2020 Published online: 04 January 2021

\section{References}

1. Xiang L, He G. Caloric restriction and antiaging effects. Ann Nutr Metab. 2011;58:42-8. https://doi.org/10.1159/000323748.

2. Martin B, Golden E, Carlson OD, Egan JM, Mattson MP, Maudsley S. Caloric restriction: impact upon pituitary function and reproduction. Ageing Res Rev. 2008;7:209-24. https://doi.org/10.1016/j.arr.2008.01.002.

3. McCay CM, Crowell MF, Maynard LA. The effect of retarded growth upon the length of life span and upon the ultimate body size. J Nutr. 1935;10:6379. https://doi.org/10.1093/jn/10.1.63

4. Xiang $Y, X u$ J, Li L, Lin $X$, Chen $X$, Zhang $X$, et al. Calorie restriction increases primordial follicle reserve in mature female chemotherapy-treated rats. Gene. 2012;493:77-82. https://doi.org/10.1016/j.gene.2011.11.019.

5. Kirkwood TBL, Shanley DP. Food restriction, evolution and ageing. Mech Ageing Dev. 2005;126(9 SPEC. ISS):1011-6. https://doi.org/10.1016/j.mad. 2005.03.021.

6. Moatt JP, Nakagawa S, Lagisz M, Walling CA. The effect of dietary restriction on reproduction: a meta-analytic perspective. BMC Evol Biol. 2016;16:1-9. https://doi.org/10.1186/s12862-016-0768-z.

7. Selesniemi K, Lee HJ, Tilly JL. Moderate caloric restriction initiated in rodents during adulthood sustains function of the female reproductive axis into advanced chronological age. Aging Cell. 2008;7:622-9. https://doi.org/10. 1111/j.1474-9726.2008.00409.x.

8. Skorupskaite K, George JT, Anderson RA. The kisspeptin-GnRH pathway in human reproductive health and disease. Hum Reprod Update. 2014;20:485500. https://doi.org/10.1093/humupd/dmu009

9. Goodman RL, Lehman MN. Kisspeptin neurons from mice to men: similarities and differences. Endocrinology. 2012;153:5105-18. https://doi. org/10.1210/en.2012-1550.

10. Takumi K, lijima N, Higo S, Ozawa H. Immunohistochemical analysis of the colocalization of corticotropin-releasing hormone receptor and glucocorticoid receptor in kisspeptin neurons in the hypothalamus of female rats. Neurosci Lett. 2012;531:40-5. https://doi.org/10.1016/j.neulet. 2012.10.010.

11. Padilla SL, Qiu J, Nestor CC, Zhang C, Smith AW, Whiddon BB, et al. AgRP to Kiss1 neuron signaling links nutritional state and fertility. Proc Natl Acad Sci U S A. 2017;114:2413-8. https://doi.org/10.1073/pnas.1621065114.

12. Roa J, Herbison AE. Direct regulation of $\mathrm{GnRH}$ neuron excitability by arcuate nucleus POMC and NPY neuron neuropeptides in female mice. Endocrinology. 2012;153:5587-99. https://doi.org/10.1210/en.2012-1470.

13. Yan H, Yang J, Marasco J, Yamaguchi K, Brenner S, Collins F, et al. Cloning and functional expression of CDNAs encoding human and rat pancreatic polypeptide receptors. Proc Natl Acad Sci U S A. 1996;93:4661-5. https://doi. org/10.1073/pnas.93.10.4661

14. Parent AS, Lebrethon MC, Gérard A, Vandersmissen E, Bourguignon JP. Leptin effects on pulsatile gonadotropin releasing hormone secretion from the adult rat hypothalamus and interaction with cocaine and amphetamine regulated transcript peptide and neuropeptide Y. Regul Pept. 2000;92:17-24. https://doi.org/10.1016/S0167-0115(00)00144-0.

15. Shimokawa I, Higami Y. Leptin signaling and aging: insight from caloric restriction. Mech Ageing Dev. 2001;122:1511-9. https://doi.org/10.1016/ S0047-6374(01)00284-6. 
16. Israel DD, Sheffer-Babila S, De Luca C, Jo YH, Liu SM, Xia Q, et al. Effects of leptin and melanocortin signaling interactions on pubertal development and reproduction. Endocrinology. 2012;153:2408-19. https://doi.org/10.1210/en.2011-1822.

17. Stincic TL, Grachev P, Bosch MA, Rønnekleiv OK, Kelly MJ. Estradiol drives the anorexigenic activity of proopiomelanocortin neurons in female mice. eNeuro. 2018;5. https://doi.org/10.1523/ENEURO.0103-18.2018.

18. True C, Verma S, Grove KL, Smith MS. Cocaine- and amphetamine-regulated transcript is a potent stimulator of gnrh and kisspeptin cells and may contribute to negative energy balance-induced reproductive inhibition in females. Endocrinology. 2013;154:2821-32. https:/doi.org/10.1210/en.2013-1156.

19. Sanchez-Garrido MA, Tena-Sempere M. Metabolic control of puberty: roles of leptin and kisspeptins. Horm Behav. 2013;64:187-94. https://doi.org/10. 1016/j.yhbeh.2013.01.014

20. True C, Kirigiti MA, Kievit P, Grove KL, Smith MS. Leptin is not the critical signal for kisspeptin or luteinising hormone restoration during exit from negative energy balance. J Neuroendocrinol. 2011;23:1099-112. https://doi. org/10.1111/j.1365-2826.2011.02144.x.

21. Caprio M, Fabbrini E, Isidori AM, Aversa A, Fabbri A. Leptin in reproduction. Trends Endocrinol Metab. 2001;12:65-72. https://doi.org/10.1016/51043-2760(00)00352-0.

22. Elias CF, Purohit D. Leptin signaling and circuits in puberty and fertility. Cell Mol Life Sci. 2013;70:841-62. https://doi.org/10.1007/s00018-012-1095-1.

23. Tena-Sempere M. Ghrelin as a pleotrophic modulator of gonadal function and reproduction. Nat Clin Pract Endocrinol Metabol. 2008;4:666-74. https:// doi.org/10.1038/ncpendmet1003

24. Forbes S, Li XF, Kinsey-Jones J, O'Byrne K. Effects of ghrelin on Kisspeptin mRNA expression in the hypothalamic medial preoptic area and pulsatile luteinising hormone secretion in the female rat. Neurosci Lett. 2009;460: 143-7. https://doi.org/10.1016/.neulet.2009.05.060.

25. Fernández-Fernández R, Tena-Sempere M, Navarro VM, Barreiro ML, Castellano $J M$, Aguilar E, et al. Effects of ghrelin upon gonadotropin-releasing hormone and gonadotropin secretion in adult female rats: in vivo and in vitro studies. Neuroendocrinology. 2006;82:245-55. https://doi.org/10.1159/000092753.

26. Vulliémoz NR, Xiao E, Xia-Zhang L, Rivier J, Ferin M. Astressin B, a nonselective corticotropin-releasing hormone receptor antagonist, prevents the inhibitory effect of ghrelin on luteinizing hormone pulse frequency in the ovariectomized rhesus monkey. Endocrinology. 2008;149:869-74. https://doi.org/10.1210/en.2007-1350.

27. Cowley MA, Smith RG, Diano S, Tschöp M, Pronchuk N, Grove KL, et al. The distribution and mechanism of action of ghrelin in the CNS demonstrates a novel hypothalamic circuit regulating energy homeostasis. Neuron. 2003;37: 649-61. https://doi.org/10.1016/S0896-6273(03)00063-1.

28. Kluge M, Schüssler P, Schmidt D, Uhr M, Steiger A. Ghrelin suppresses secretion of luteinizing hormone ( $\mathrm{LH})$ and follicle-stimulating hormone (FSH) in women. J Clin Endocrinol Metab. 2012;97. https://doi.org/10.1210/jc.2011-2607.

29. Wolfe A, Divall S, Wu S. The regulation of reproductive neuroendocrine function by insulin and insulin-like growth factor-1 (IGF-1). Front Neuroendocrinol. 2014;35:558-72. https://doi.org/10.1016/j.yfrne.2014.05.007.

30. Sliwowska JH, Fergani C, Gawałek M, Skowronska B, Fichna P, Lehman MN Insulin: its role in the central control of reproduction. Physiol Behav. 2014; 133:197-206. https://doi.org/10.1016/j.physbeh.2014.05.021.

31. Ronnekleiv OK, Qiu J, Kelly MJ. Arcuate Kisspeptin neurons coordinate reproductive activities with metabolism. Semin Reprod Med. 2019;37:13140. https://doi.org/10.1055/s-0039-3400251.

32. Dorn C, Mouillet JF, Yan X, Ou Q, Sadovsky Y. Insulin enhances the transcription of luteinizing hormone- $\beta$ gene. Am J Obstet Gynecol. 2004; 191:132-7. https://doi.org/10.1016/j.ajog.2004.01.054.

33. Li L, Cai FY, Jie XJ, Chun CX, Hao LX, Li LL. Caloric restriction promotes the reproductive capacity of female rats via modulating the level of insulin-like growth factor-1 (IGF-1). Gen Comp Endocrinol. 2011;174:232-7. https://doi. org/10.1016/j.ygcen.2011.09.005.

34. Bezerra MÉS, Barberino RS, Menezes VG, Gouveia BB, Macedo TJS, Santos JMS, et al. Insulin-like growth factor-1 (IGF-1) promotes primordial follicle growth and reduces DNA fragmentation through the phosphatidylinositol 3-kinase/protein kinase B (PI3K/AKT) signalling pathway. Reprod Fertil Dev. 2018:30:1503-13. https://doi.org/10.1071/RD17332.

35. Zhou P, Baumgarten SC, Wu Y, Bennett J, Winston N, Hirshfeld-Cytron J, et al. IGF-I signaling is essential for FSH stimulation of AKT and steroidogenic genes in granulosa cells. Mol Endocrinol. 2013;27:511-23. https://doi.org/10.1210/me.2012-1307.

36. Yang JA, Yasrebi A, Snyder M, Roepke TA. The interaction of fasting, caloric restriction, and diet-induced obesity with $17 \beta$-estradiol on the expression of
KNDy neuropeptides and their receptors in the female mouse. Mol Cell Endocrinol. 2016;437:35-50. https://doi.org/10.1016/.mce.2016.08.008.

37. Park S, Mori R, Shimokawa I. The fat regulator neuropeptide $Y$ and caloric restriction. Aging (Albany NY). 2017;9:2243-4. https://doi.org/10.18632/aging.101338

38. Matsuyama S, Kimura K. Regulation of gonadotropin secretion by monitoring energy availability. Reprod Med Biol. 2015;14:39-47. https://doi. org/10.1007/s12522-014-0194-0.

39. Kinoshita M, Moriyama R, Tsukamura H, Maeda Kl. A rat model for the energetic regulation of gonadotropin secretion: role of the glucose-sensing mechanism in the brain. In: Domestic Animal Endocrinology: Elsevier Inc; 2003. p. 109-20. https://doi.org/10.1016/S0739-7240(03)00050-X.

40. Deura C, Minabe S, Ikegami K, Inoue N, Uenoyama Y, Maeda Kl, et al. Morphological analysis for neuronal pathway from the hindbrain ependymocytes to the hypothalamic kisspeptin neurons. J Reprod Dev. 2019;65:129-37. https://doi.org/10.1262/jrd.2018-122.

41. Masoro EJ. Overview of caloric restriction and ageing. Mech Ageing Dev. 2005;126(9 SPEC. ISS):913-22. https://doi.org/10.1016/j.mad.2005.03.012.

42. Li L, Fu YC, Xu JJ, Lin XH, Chen XC, Zhang XM, et al. Caloric restriction promotes the reserve of follicle pool in adult female rats by inhibiting the activation of mammalian target of rapamycin signaling. Reprod Sci. 2015;22: 60-7. https://doi.org/10.1177/1933719114542016.

43. Słuczanowska-Głąbowska S, Laszczyńska M, Piotrowska K, Grabowska M, Grymuła K, Ratajczak MZ. Caloric restriction increases ratio of estrogen to androgen receptors expression in murine ovaries - potential therapeutic implications. J Ovarian Res. 2015;8. https:/doi.org/10.1186/s13048-015-0185-8.

44. Walsh SW, Mehta JP, McGettigan PA, Browne JA, Forde N, Alibrahim RM, et al. Effect of the metabolic environment at key stages of follicle development in cattle: focus on steroid biosynthesis. Physiol Genomics. 2012;44:504-17. https://doi.org/10.1152/physiolgenomics.00178.2011.

45. Hussein HA, Abdel-Raheem SM. Effect of feed intake restriction on reproductive performance and pregnancy rate in Egyptian buffalo heifers. Trop Anim Health Prod. 2013;45:1001-6. https://doi.org/10.1007/s11250-012-0324-9.

46. Lujan ME, Krzemien AA, Reid RL, Van Vugt DA. Caloric restriction inhibits steroid-induced gonadotropin surges in ovariectomized rhesus monkeys. Endocrine. 2005;27:25-31. https://doi.org/10.1385/endo:27:1:025.

47. McShane TM, Wise PM. Life-long moderate caloric restriction prolongs reproductive life span in rats without interrupting estrous cyclicity: effects on the gonadotropin-releasing hormone/luteinizing hormone axis. Biol Reprod. 1996;54:70-5. https://doi.org/10.1095/biolreprod54.1.70.

48. Luo Q, Li W, Li M, Zhang X, Zhang H. Leptin/leptinR-kisspeptin/kiss1r-GnRH pathway reacting to regulate puberty onset during negative energy balance. Life Sci. 2016;153:207-12. https://doi.org/10.1016/j.lfs.2016.03.048.

49. Cortés ME, Carrera B, Rioseco H, Pablo del Río J, Vigil P. The role of Kisspeptin in the onset of puberty and in the ovulatory mechanism: a mini-review. J Pediatr Adolesc Gynecol. 2015;28:286-91. https:/doi.org/10.1016/.jpag.2014.09.017.

50. Roa J, Barroso A, Ruiz-Pino F, Vázquez MJ, Seoane-Collazo P, MartínezSanchez $\mathrm{N}$, et al. Metabolic regulation of female puberty via hypothalamic AMPK-kisspeptin signaling. Proc Natl Acad Sci U S A. 2018;115:E10758-67. https://doi.org/10.1073/pnas.1802053115.

51. Navarro VM, Ruiz-Pino F, Sánchez-Garrido MA, García-Galiano D, Hobbs SJ, Manfredi-Lozano M, et al. Role of neurokinin B in the control of female puberty and its modulation by metabolic status. J Neurosci. 2012;32:238897. https://doi.org/10.1523/JNEUROSCl.4288-11.2012.

52. Manfredi-Lozano M, Roa J, Ruiz-Pino F, Piet R, Garcia-Galiano D, Pineda R, et al. Defining a novel leptin-melanocortin-kisspeptin pathway involved in the metabolic control of puberty. Mol Metab. 2016;5:844-57. https://doi.org/ 10.1016/j.molmet.2016.08.003.

53. López M. Hypothalamic AMPK and energy balance. Eur J Clin Investig. 2018; 48. https://doi.org/10.1111/eci.12996.

54. BALL ZB, BARNES RH, VISSCHER MB. The effects of dietary caloric restriction on maturity and senescence, with particular reference to fertility and longevity. Am J Phys. 1947;150:511-9. https://doi.org/10.1152/ajplegacy.1947.150.3.511.

55. Garcia DN, Saccon TD, Pradiee J, Rincón JAA, Andrade KRS, Rovani MT, et al. Effect of caloric restriction and rapamycin on ovarian aging in mice. GeroScience. 2019;41:395-408. https://doi.org/10.1007/s11357-019-00087-x.

56. [Protective effects of caloric restriction on ovarian function] - PubMed. https://pubmed.ncbi.nlm.nih.gov/24406130/. Accessed 28 Sept 2020.

57. Liu WJ, Zhang XM, Wang N, Zhou XL, Fu YC, Luo LL. Calorie restriction inhibits ovarian follicle development and follicle loss through activating SIRT1 signaling in mice. Eur J Med Res. 2015;20. https://doi.org/10.1186/ s40001-015-0114-8. 
58. Zhou XL, Xu JJ, Ni YH, Chen XC, Zhang HX, Zhang XM, et al. SIRT1 activator (SRT1720) improves the follicle reserve and prolongs the ovarian lifespan of diet-induced obesity in female mice via activating SIRT1 and suppressing mTOR signaling. J Ovarian Res. 2014;7. https:// doi.org/10.1186/s13048-014-0097-z.

59. Wang N, Luo LL, Xu JJ, Xu MY, Zhang XM, Zhou XL, et al. Obesity accelerates ovarian follicle development and follicle loss in rats. Metabolism. 2014;63:94-103. https://doi.org/10.1016/j.metabol.2013.09.001.

60. Tilly $J$, Sinclair DA. Germline energetics, aging, and female infertility. Cell Metab. 2013;17:838-50. https://doi.org/10.1016/j.cmet.2013.05.007.

61. Selesniemi K, Lee HJ, Muhlhauser A, Tilly JL. Prevention of maternal agingassociated oocyte aneuploidy and meiotic spindle defects in mice by dietary and genetic strategies. Proc Natl Acad Sci U S A. 2011;108:12319-24. https://doi.org/10.1073/pnas.1018793108.

62. Zhang J, Fang L, Lu Z, Xiong J, Wu M, Shi L, et al. Are sirtuins markers of ovarian aging? Gene. 2016;575:680-6. https://doi.org/10.1016/j.gene.2015.09.043.

63. Long GY, Yang JY, Xu JJ, Ni YH, Zhou XL, Ma JY, et al. SIRT1 knock-in mice preserve ovarian reserve resembling caloric restriction. Gene. 2019;686:194202. https://doi.org/10.1016/j.gene.2018.10.040.

64. Kim JM, Yoon YD, Tsang BK. Involvement of the Fas/Fas ligand system in p53-mediated granulosa cell apoptosis during follicular development and atresia. Endocrinology. 1999;140:2307-17. https://doi.org/10.1210/ endo.140.5.6726.

65. Tilly JL, Tilly Kl, Kenton ML, Johnson AL. Expression of members of the BCl-2 gene family in the immature rat ovary: equine chorionic gonadotropinmediated inhibition of granulosa cell apoptosis is associated with decreased bax and constitutive $\mathrm{BCl}-2$ and $\mathrm{BCl}-\mathrm{Xlong}$ messenger ribonucleic acid levels. Endocrinology. 1995;136:232-41. https://doi.org/10.1210/endo.136.1.7828536.

66. Ghafari F, Pelengaris S, Walters E, Hartshorne GM. Influence of p53 and genetic background on prenatal oogenesis and oocyte attrition in mice. Hum Reprod. 2009;24:1460-72. https://doi.org/10.1093/humrep/dep022.

67. Rimon-Dahari N, Yerushalmi-Heinemann L, Alyagor L, Dekel N. Ovarian folliculogenesis. Results Probl Cell Differ. 2016;58:167-90. https://doi.org/10 1007/978-3-319-31973-5_7.

68. Meynet O, Ricci JE. Caloric restriction and cancer: molecular mechanisms and clinical implications. Trends Mol Med. 2014;20:419-27. https://doi.org/ 10.1016/j.molmed.2014.05.001.

69. Santoro N. The menopausal transition. In: American Journal of Medicine: Elsevier Inc.; 2005. p. 8-13. https://doi.org/10.1016/j.amjmed.2005.09.008.

70. Depmann M, Faddy MJ, Van Der Schouw YT, Peeters PHM, Broer SL, Kelsey TW, et al. The relationship between variation in size of the primordial follicle pool and age at natural menopause. J Clin Endocrinol Metab. 2015;100: E845-51. https://doi.org/10.1210/jc.2015-1298.

71. Elias SG, Van Noord PAH, Peeters PHM, Den Tonkelaar I, Grobbee DE. Caloric restriction reduces age at menopause: the effect of the 1944-1945 Dutch famine. Menopause. 2018;25:1232-7. https://doi.org/10.1097/GME. 0000000000001224

72. Sirotkin AV, Florkovičová IK, Švarcová OØ, Rafay J, Laurincik J, Harrath AH. Caloric restriction and IGF-I administration promote rabbit fecundity: possible interrelationships and mechanisms of action. Theriogenology. 2017; 90:252-9. https://doi.org/10.1016/j.theriogenology.2016.12.017.

73. Vitzthum VJ, Spielvogel $H$, Thornburg J. Interpopulational differences in progesterone levels during conception and implantation in humans. Proc Natl Acad Sci U S A. 2004;101:1443-8. https://doi.org/10.1073/pnas.0302640101.

74. Barbieri RL. The endocrinology of the menstrual cycle. Methods Mol Biol. 2014;1154:169-80. https://doi.org/10.1007/978-1-4939-0659-8_7.

75. Erickson GF, Garzo VG, Magoffin DA. Insulin-like growth factor-I regulates aromatase activity in human granulosa and granulosa luteal cells. J Clin Endocrinol Metab. 1989;69:716-24. https://doi.org/10.1210/jcem-69-4-716.

76. Adashi EY, Resnick CE, Svoboda ME, Van Wyk JJ. Somatomedin-C synergizes with follicle-stimulating hormone in the acquisition of progestin biosynthetic capacity by cultured rat granulosa cells. Endocrinology. 1985; 116:2135-42. https://doi.org/10.1210/endo-116-6-2135.

77. Warren MP. Effects of undernutrition on reproductive function in the human. Endocr Rev. 1983;4:363-77. https://doi.org/10.1210/edrv-4-4-363.

78. Elias SG, van Noord PAH, Peeters PHM, den Tonkelaar I, Kaaks R, Grobbee DE. Menstruation during and after caloric restriction: the 1944-1945 Dutch famine. Fertil Steril. 2007:88(4 SUPPL):1101-7. https://doi.org/10.1016/j. fertnstert.2006.12.043.
79. Lumey LH. Compensatory placental growth after restricted maternal nutrition in early pregnancy. Placenta. 1998;19:105-11. https://doi.org/10. 1016/S0143-4004(98)90105-9.

80. Roseboom T, de Rooij S, Painter R. The Dutch famine and its long-term consequences for adult health. Early Hum Dev. 2006;82:485-91. https://doi. org/10.1016/j.earlhumdev.2006.07.001.

81. Harper JL, Caesar GA, Pennington KA, Davis JW, Schulz LC. Placental changes caused by food restriction during early pregnancy in mice are reversible. Reproduction. 2015;150:165-72. https://doi.org/10.1530/REP-15-0010.

82. Harrath AH, Alrezaki A, Mansour L, Alwasel SH, Palomba S. Food restriction during pregnancy and female offspring fertility: adverse effects of reprogrammed reproductive lifespan. J Ovarian Res. 2017;10. https://doi.org/ 10.1186/s13048-017-0372-X.

83. Yarde F, Broekmans FJ, van der Pal-de Bruin KM, Schönbeck Y, te Velde ER, Stein $A D$, et al. Prenatal famine, birthweight, reproductive performance and age at menopause: the Dutch hunger winter families study. Hum Reprod. 2013;28:3328-36. https://doi.org/10.1093/humrep/det331.

84. Fenichel RM, Warren MP. Anorexia, bulimia, and the athletic triad: evaluation and management. Current Osteoporosis Reports. 2007;5:160-4. https://doi. org/10.1007/s11914-007-0011-3.

85. Marzouk TM, Sayed Ahmed WA. Effect of dietary weight loss on menstrual regularity in obese young adult women with polycystic ovary syndrome. J Pediatr Adolesc Gynecol. 2015;28:457-61. https:/doi.org/10.1016/j.jpag.2015.01.002.

86. Lope V, Martín M, Castelló A, Ruiz A, Casas AM, Baena-Cañada JM, et a. Overeating, caloric restriction and breast cancer risk by pathologic subtype: the EPIGEICAM study. Sci Rep. 2019;9. https://doi.org/10.1038/s41598-019-39346-4.

87. Belkacemi L, Michael Nelson D, Desai M, Ross MG. Maternal undernutrition influences placental-fetal development. Biol Reprod. 2010;83:325-31. https:// doi.org/10.1095/biolreprod.110.084517.

88. Hoffman DJ, Reynolds RM, Hardy DB. Developmental origins of health and disease: current knowledge and potential mechanisms. Nutr Rev. 2017;75: 951-70. https://doi.org/10.1093/nutrit/nux053.

89. Roseboom TJ, Painter RC, Van Abeelen AFM, Veenendaal MVE, De Rooij SR. Hungry in the womb: what are the consequences? Lessons from the Dutch famine. Maturitas. 2011;70:141-5. https://doi.org/10.1016/j. maturitas.2011.06.017

90. Bernal AB, Vickers MH, Hampton MB, Poynton RA, Sloboda DM. Maternal undernutrition significantly impacts ovarian follicle number and increases ovarian oxidative stress in adult rat offspring. PLoS One. 2010;5. https://doi. org/10.1371/journal.pone.0015558.

91. Rae MT, Kyle CE, Miller DW, Hammond AJ, Brooks AN, Rhind SM. The effects of undernutrition, in utero, on reproductive function in adult male and female sheep. Anim Reprod Sci. 2002;72:63-71. https://doi.org/10.1016/ S0378-4320(02)00068-4.

92. Painter RC, Westendorp RGJ, De Rooij SR, Osmond C, Barker DJP, Roseboom TJ. Increased reproductive success of women after prenatal undernutrition. Hum Reprod. 2008;23:2591-5. https://doi.org/10.1093/humrep/den274.

93. Lumey LH, Stein AD. Increased reproductive success of women after prenatal undernutrition? Hum Reprod. 2009;24:491. https://doi.org/10.1093/ humrep/den394.

94. Dumesic DA, Lobo RA. Cancer risk and PCOS. Steroids. 2013;78:782-5. https://doi.org/10.1016/j.steroids.2013.04.004.

95. EWCM VD, Roelfsema F, Veldhuis JD, Hogendoorn S, Westenberg J, Helmerhorst FM, et al. Retention of estradiol negative feedback relationship to LH predicts ovulation in response to caloric restriction and weight loss in obese patients with polycystic ovary syndrome. Am J Physiol - Endocrinol Metab. 2004:286(4):49-4. https://doi.org/10.1152/ajpendo.00377.2003.

96. Diane A, Vine DF, Donald Heth C, Russell JC, Proctor SD, David PW. Prior caloric restriction increases survival of prepubertal obese- and PCOS-prone rats exposed to a challenge of time-limited feeding and physical activity. J Appl Physiol. 2013;114:1158-64. https://doi.org/10. 1152/japplphysiol.01127.2012.

97. EWCM VD, Roelfsema F, Veldhuis JD, Helmerhorst FM, Frölich M, Edo Meinders A, et al. Increase in daily LH secretion in response to short-term calorie restriction in obese women with PCOS. Am J Physiol - Endocrinol Metab. 2002;282(4):45-4. https://doi.org/10.1152/ajpendo.00458.2001.

\section{Publisher's Note}

Springer Nature remains neutral with regard to jurisdictional claims in published maps and institutional affiliations. 